\title{
Seismic Isolation for Protecting Historical Buildings: A Case Study
}

\author{
Michele D'Amato ${ }^{1}$, Rosario Gigliotti ${ }^{2}$ and Raffaele Laguardia ${ }^{2 *}$ \\ ${ }^{1}$ Department of European and Mediterranean Cultures (Architecture, Environment and Cultural Heritage), University of \\ Basilicata, Matera, Italy, ${ }^{2}$ Department of Structural and Geotechnical Engineering, Sapienza University of Rome, Rome, Italy
}

OPEN ACCESS

Edited by:

Izuru Takewaki,

Kyoto University, Japan

Reviewed by:

Luigi Di Sarno,

University of Sannio, Italy

Fabrizio Paolacci,

Roma Tre University, Italy

*Correspondence:

Raffaele Laguardia

raffaele.laguardia@uniroma1.it

Specialty section:

This article was submitted to

Earthquake Engineering,

a section of the journal

Frontiers in Built Environment

Received: 15 February 2019

Accepted: 18 June 2019

Published: 03 July 2019

Citation:

D'Amato M, Gigliotti $R$ and Laguardia $R$ (2019) Seismic Isolation for Protecting Historical Buildings: A

Case Study. Front. Built Environ. 5:87.

doi: 10.3389/fbuil.2019.00087
The protection of cultural heritage from seismic risk is an open issue due to the difficulties in finding technical solutions allowing a balance between their effectiveness and invasiveness. Among the available protection techniques, seismic isolation is one of the most suitable obtaining a significant performance improvement by acting on a limited portion of the structure. In this paper, it is shown an application of such technique on a reinforced concrete frame building cataloged as of historical interest by Italian Ministry of Cultural Heritage. It was realized in 30's representing the "Modern Style" of Italian Architecture, also known as Italian Rationalism, and designed only for vertical loads without any specific regulation for lateral loads. Geometry, material properties and reinforcements characteristics have been derived from an extensive investigation campaign. By the means of a FEM 3D model they are simulated among them the seismic responses of both existing and retrofitted building through a seismic isolation system composed by elastomeric and sliding isolators. Furthermore, a new methodology for estimating the seismic capacity exhibited by the structure in the past is presented and applied.

Keywords: cultural heritage, monuments, reinforced concrete, seismic vulnerability, seismic retrofit, seismic isolated buildings

\section{INTRODUCTION}

To date, the strategy of seismic isolation as earthquake-resistant technique applied on existing buildings is become very common all over the World. It is based on the concept of lengthening the natural period of the structure from the predominant frequency of the ground motions, significantly reducing the transmitted acceleration to the superstructure (Kelly, 1986; Alhan and Gavin, 2004; Ibrahim, 2008). The isolation plane is generally realized above the foundation and it consists of devices capable of reducing the lateral stiffness of the superstructure combing recentering and energy dissipation action. In this way, the seismic demand on the superstructure is drastically reduced and the performance requirements are satisfied by strongly limiting or nullifying the elements damage. In addition, this strategy requires spaces of small dimensions to be realized, and in many cases not even requiring the evacuation of the occupants.

In Italy, during the last 30 years, the seismic isolation applications have been increased more and more representing, nowadays, a common technique of structural design. A proof of this is given by the fact that the Italian Design Code (NTC, 2008) and its recent update (NTC, 2018) recognize the 
seismic isolation as standard application in buildings design. First applications of this strategy may be found in Mokha et al. (1996), Martelli and Forni (1998), Kawamura et al. (2000), Luca et al. (2001), Kelly (2002), Braga et al. (2005), Tomazevic et al. (2009), and Lignola et al. (2016).

Commonly, seismic isolation is used for retrofitting of Reinforced Concrete (RC) existing buildings, since very often they were designed only for vertical loads without any detailing rule for ductility, as highlighted in some recent studies such as, among the others, (Laterza et al., 2017a). In these cases, the seismic isolation is preferred to widespread and more invasive local interventions, consisting in strengthening and improving the confinement of the elements (Braga et al., 2006; D’Amato et al., 2012a,b; Laterza et al., 2017b; Caprili et al., 2018; Faqeer et al., 2018), or consisting in adding new structural elements in order to carry the seismic loads and dissipate energy (Ciampi et al., 1995; Di Sarno and Manfredi, 2010, 2012; Mazza and Vulcano, 2014; Laguardia et al., 2017; Braga et al., 2019).

This paper presents the application of the seismic base isolation for retrofitting an existing RC building, in accordance to the Italian Design Code (NTC, 2008). The case study chosen is the public building named "Archivio di Stato" (State Archive) designed and built during the 30's in Potenza, a city located along the Apennine chain with the highest seismic hazard in Italy. Moreover, due to its architectural importance, the considered building is protected by the Italian Ministry of Cultural Heritage. Indeed, it is representative of the "Modern Style" of Italian Architecture, also known as Italian Rationalism. The numerical simulations are obtained through response spectrum analyses for Fixed-Base (FB) and Base-Isolated (BI) model, considering also the impact of the variability of the friction coefficient of sliding devices.

In this article, it is therefore highlighted the effectiveness of the isolating system in order to retrofit historical buildings. In the case analyzed, several local reinforcements are required to gain the assumed seismic performance level, given the need to reduce the invasiveness of the intervention, the number and the impact of these interventions by varying the retrofit strategy is discussed. Moreover, in this study it is proposed a new and simplified methodology to estimate the structural capacity on the basis of the seismic performances exhibited by the building in the past occurred earthquakes. Precisely, the estimation of the occurred seismic action at building base stems from ground motions (GMs) available and recorded in the site surrounding area. The main idea of the proposed simplified methodology is the following: if a fixed base-building has experienced an earthquake in the past with negligible or limited damages, the seismic intensity of that earthquake may be intended as an experimental proof related to the building capacity, or rather, to the capacity of the superstructure portion of the base-isolated building. The new methodology can be used as a fast and useful tool to roughly assess the seismic performances of buildings sample in a certain area, identifying the most suitable ones for a seismic isolation strategy, implying negligible or limited damages of the superstructure. The so-estimated seismic capacity can be also used as an experimental threshold to be considered in validating implemented numerical models for seismic assessment of a structure.

\section{CASE STUDY- "ARCHIVIO DI STATO” OF POTENZA, ITALY (1930)}

The "Archivio di Stato" (State Archive) was designed and realized in the 30's by the architect Ernesto Puppo (1904-1987), one of the principal exponents of Italian Rationalism Movement. It is located in the city of Potenza along a hillside on a steep slope toward the City center and used as State Archive. The building consists of RC frame structures composing three intersecting volumes with a markedly non-symmetric geometry. In Figure 1 are shown some views and technical drawings of the considered buildings. In particular, in Figure 1A they are reported a transversal and a longitudinal section of the building, where it can be appreciated the hillside disposition and the relevant irregularity in elevation. The Italian Ministry of Cultural Heritage has recently added this building among those to be protected due to its architectural relevance, even considering the construction period and the urban context in which it is inserted, that can be appreciated in the photos of Figure 1B. Figure 1C shows the current abandonment state of the building due to the slight damages suffered during the Irpinia earthquake on $23 / 11 / 1980$, after that it was closed.

This building is of considerable importance also because it was one of the first realized in Italy with RC frameresisting structure by the "Cooperativa Muratori e Cementisti di Ravenna" construction company between 1936 and 1939. The frame structure is characterized by columns with square or rectangular sections with deep or flat beams, the floors slabs are made of reinforced concrete with predominant unidirectional warping. The building has three underground floors and six floors above ground with an average interstory height of about $4.5 \mathrm{~m}$. Due to the strong architectural variations in height, the floors surfaces significantly vary with height. Table 1 summarizes these geometrical details, where the Level 0 corresponds to the floor accessible from the main street facing the building. Moreover, each column is founded on a deep well-foundation and connected by a beam gridwork placed at a height of $-9.6 \mathrm{~m}$, while no connection is present for the columns of the lower part of the building, founded at $-13.80 \mathrm{~m}$. Finally, infills are made of bricks and placed both in the external frames and in some internal frames.

\section{Materials Properties and Concrete Elements Details}

In order to characterize this building, in addition to an in-depth geometrical investigation, it has been also necessary to perform an extensive investigation campaign on material properties and structural reinforcement detailing disposition. To this regard, it should be noted that, at the time of construction, there were few code indications for reinforced concrete constructions or available consolidated calculation schemes. Therefore, the survey campaign has played an important role to define the structural 

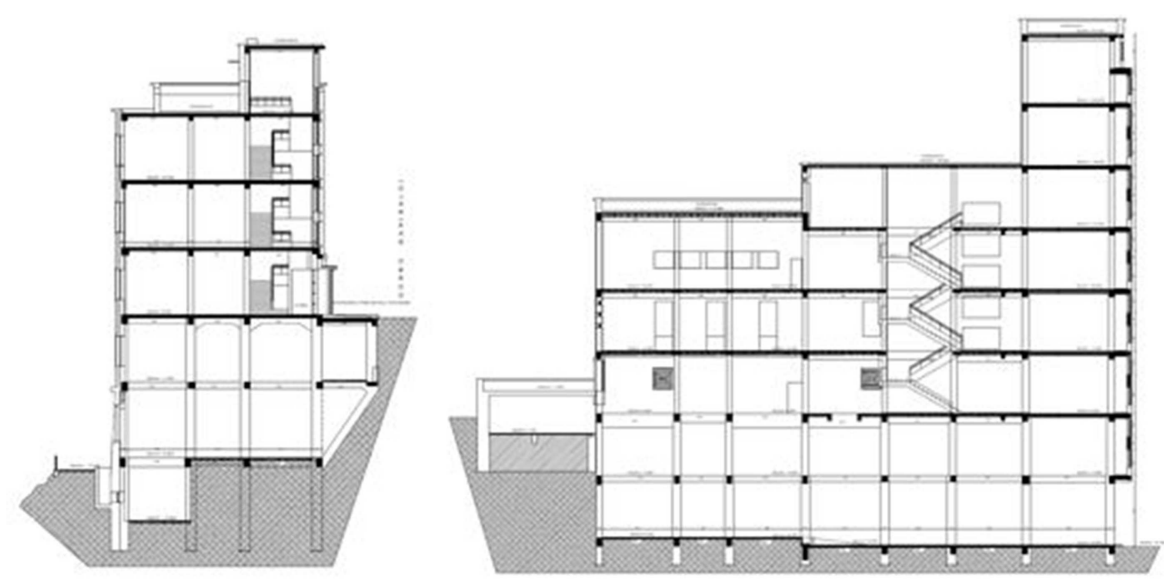

A
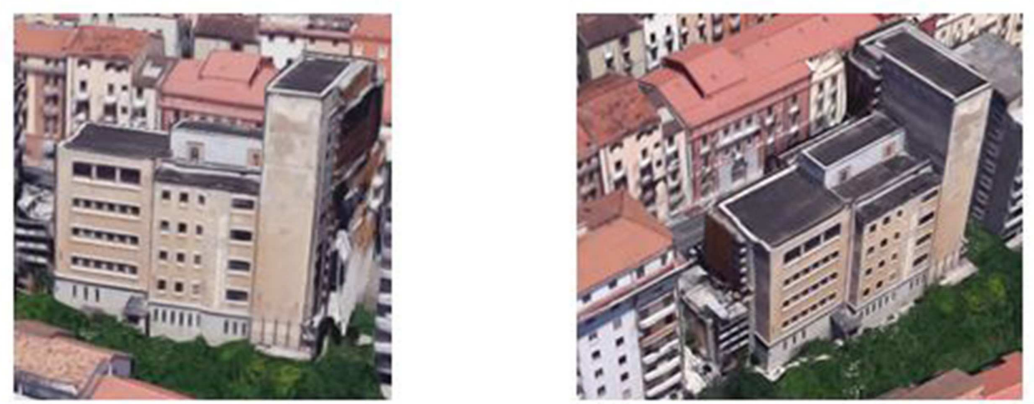

B
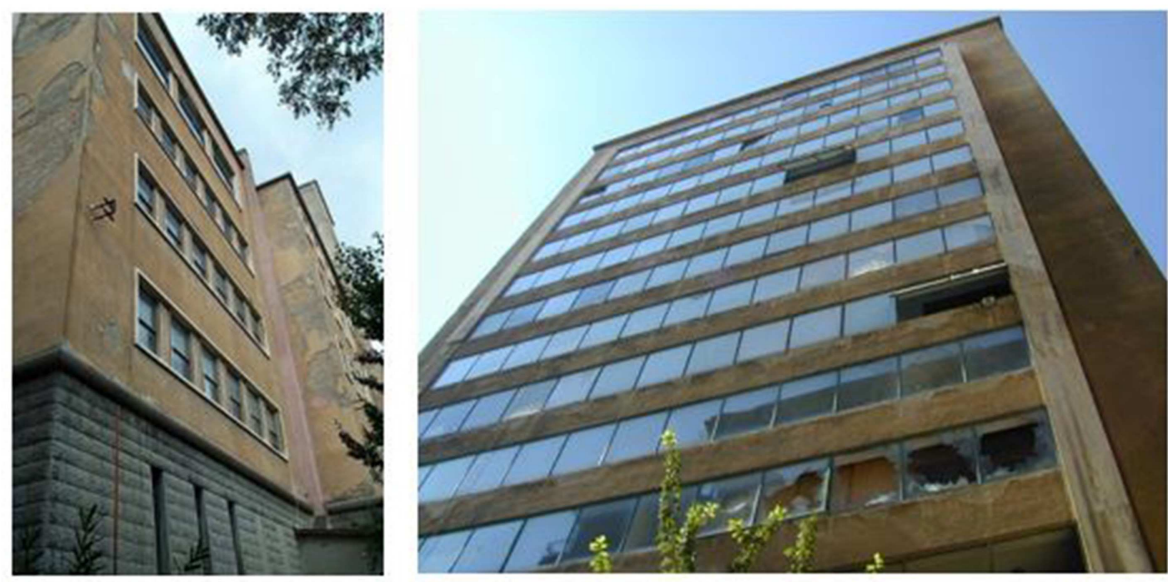

C

FIGURE 1 | Some images of the considered case study. (A) Transversal and longitudinal section of the building, (B) images from Google Maps (2019), and (C) current conditions of the building.

characteristics of the case study. Totally, the investigations campaign consisted of sampling of 13 reinforcing steel bars specimens, 21 concrete core drilled, 62 SONREB tests, and over 300 sections pacometric investigations for construction details. In this study, since the elaboration data is still in progress, only the results of the material properties measured with laboratory tests on concrete and rebars samples are illustrated. More in detail, laboratory tests on concrete samples (Figure 2B) extracted from beams and columns were performed to evaluate the compressive strength of concrete. The mean values of compressive strength $\left(\mathrm{f}_{\mathrm{cm}}\right)$ and the coefficient of variation $(\mathrm{CV})$ of the sample are reported in Figure 2A. Since a different homogeneity along the building height was observed, the measured compressive strengths were divided in two different groups (Figure 2A): Group 1 from height of $-9.6-0.0 \mathrm{~m}$, having an average value of $24.2 \mathrm{MPa}$ measured on $\mathrm{n}$. 11 concrete core samples; and 
TABLE 1 | Floor surfaces, plan and interstory heights of the "Archivio di Stato" building.

\begin{tabular}{lccc}
\hline Level & Relative height [m] & Interstory height [m] & Floor area $\left.\mathbf{m}^{2}\right]$ \\
\hline Level -3 & -13.80 & 4.20 & $\cong 113$ \\
Level -2 & -9.60 & 5.10 & $\cong 648$ \\
Level -1 & -4.50 & 4.50 & $\cong 648$ \\
Level 0 & 0.00 & 4.50 & $\cong 648$ \\
Level +1 & 4.50 & 4.50 & $\cong 648$ \\
Level +2 & 9.00 & 4.50 & $\cong 648$ \\
Level +3 & 13.50 & 4.50 & $\cong 648$ \\
Level +4 & 18.00 & 4.50 & $\cong 190$ \\
Level +5 & 22.50 & 5.00 & $\cong 114$ \\
Level +6 & 27.50 & - & $\cong 114$ \\
\hline
\end{tabular}

Group 2, having a compressive strength of $18.8 \mathrm{MPa}$, from floor having $4.5 \mathrm{~m}$ height up to the roof. The so obtained compressive strengths, given the height differentiation, have been used for both beams and columns.

As regards the steel reinforcements, in situ investigations showed that, according to the RC existing buildings realized in 30 's, only smooth bars were applied. A total of 13 samples were extracted (Figure 2C), 3 from hoops of $6 \mathrm{~mm}$ diameter, and 15 from longitudinal bars having a diameter between 8 and $16 \mathrm{~mm}$. Figure $2 \mathrm{~A}$ reports also the average tensile strength of the steel samples measured with laboratory tests. The values are separately reported for longitudinal bars and for hoops. The obtained average values are compatible with the Steel strength class Aq 42, very common in the construction period of the building (Verderame et al., 2001).

Construction details of beams and columns were measured with in situ pacometric measurements and visual inspections of reinforcements by locally removing the concrete cover. A simulated design in accordance with the design practice of that period was also performed in order to compare the obtained results with those measured through the experimental campaign. Since a good agreement was obtained, the simulated design was extended to all RC elements of the building. More in detail, 2.5 and $6 \mathrm{kN} / \mathrm{m}^{2}$ were used as variable loads acting at the different floors for designing the reinforcements of decks and beams in according to simple schemes of continuous beams, as usual in the design practice. On the contrary, for columns no specific design scheme was adopted, since they were designed only for vertical loads without any lateral action for taking into account the earthquake effects. Therefore, it has been reasonable to design longitudinal and transverse reinforcements by assuming the detailing rules provided in the Italian Royal Decree (R.D., 1939), that is the design code temporally closer to the years of construction of the building. In particular, it gave the provision of assigning to $\mathrm{RC}$ columns an amount of longitudinal bars equal to $0.8 \%$ of $A_{c}$ if $A_{c}<2,000 \mathrm{~cm}^{2}$, and equal to $0.5 \%$ of $A_{c}$ if $A_{c}>5,000$ $\mathrm{cm}^{2}$, where $A_{c}$ is the column gross area. Between $A_{c}=2,000 \mathrm{~cm}^{2}$ and $A_{c}=5,000 \mathrm{~cm}^{2}$ a linear interpolation was allowed. As for the hoops, on the basis of the obtained measurements with the pacometric tests, the spacing has been considered equal to $25 \mathrm{~cm}$, slightly higher than the minimum requirements of R.D. (1939).
For completeness sake, Figure 3 illustrates the reinforcement details obtained for some columns and beams.

\section{NUMERICAL MODELS}

Figure 4A depicts the FEM model implemented in SAP 2000 software (Computers Structures Inc, 2015) for the numerical simulations of the existing building fully fixed at the base. Specifically, beams and columns have been modeled using linear elastic frames, while the decks have been modeled with shell elements having orthotropic stiffness to consider the actual heights, while the soil pressure of the underground building portions have been neglected. Finally, in order to take account of the section cracking occurring during the seismic excitation, the flexural and shear stiffness of primary columns and beams have been both reduced of $50 \%$, in accordance with the maximum cracking level allowed by the Italian code (NTC, 2008).

In Figure 4B the base-isolated model is reported. The added elements, such as the rigid steel deck placed above the devices and the others beams, have been modeled also with linear elastic frames. The isolating system, as illustrated and detailed later in Figure 9, is composed by elastomeric and friction isolators, both modeled as linear link elements, whose stiffness corresponds to the secant one at the design displacement for the considered design limit state.

\section{SITE SEISMIC HAZARD AND RESPONSE SPECTRA}

The site seismic hazard and response spectra considered in the numerical simulations are shown in Figure 5. Precisely, Figure 5A reports the parameters defining the seismic action in terms of seismic spectra referred to a rigid soil (Type A) for each Limit State considered by the Italian design code (NTC, 2008), that are: Operativity Limit State (OLS), Damage Limit State $(D L S)$, Life-SafetyLimit State (LSLS), Collapse Limit State $(C L S)$. The site seismic hazard is considered for a reference period of $V_{R}$ of 50 years (Nominal Life $V_{N}=50$ years and Coefficient of Use $C_{U}=1$ ), where: $T_{R}$ is the return period, $a_{g}$ is the maximum soil accelerations in the case of rock soil, $F_{0}$ is the maximum amplification of the spectrum, $T_{c}^{*}$ is the transition period between constant acceleration and constant velocity part of the spectrum.

In Figure 5B are reported the elastic response spectra according to NTC (2008) for the case analyzed, by considering a ground of Type $C$ and a conventional viscous damping ratio $\xi=5 \%$. In order to perform linear analyses, the Italian code (NTC, 2008) suggests to keep in count the energy dissipated by the isolating system using an appropriate design spectrum. This spectrum is obtained by reducing of a factor $\eta=\sqrt{\frac{10}{\left(5+\xi_{e s i}\right)}}$ the spectral ordinates with period higher than $0.8^{*} T_{i s}$ (that is the range of isolating system vibrations periods), where $\xi_{e s i}$ is the equivalent viscous damping ratio of the isolating system for the design horizontal displacement. In accordance with this, Figure 5C reports the so-obtained design spectra, where the equivalent $\xi_{\text {esi }}$ for each limit state is numerically reported in Figure 9. 


\begin{tabular}{|c|c|c|c|}
\hline \multicolumn{5}{|c|}{ Concrete core samples } \\
\hline Group & $n$. & $C V$ & $f_{c m}\left[\mathrm{~N} / \mathrm{mm}^{2}\right]$ \\
\hline 1 & 11 & 0.2 & 24.2 \\
\hline 2 & 10 & 0.1 & 18.8 \\
\hline \multicolumn{5}{|c|}{ Steel bar samples } \\
\hline Diameter & $n$. & $C V$ & $f_{y=3}\left[\mathrm{~N} / \mathrm{mm}^{2}\right]$ \\
\hline$\phi 10-\phi 20$ & 10 & 0.084 & 353.18 \\
\hline$\phi 6$ & 3 & 0.09 & 352.7 \\
\hline
\end{tabular}

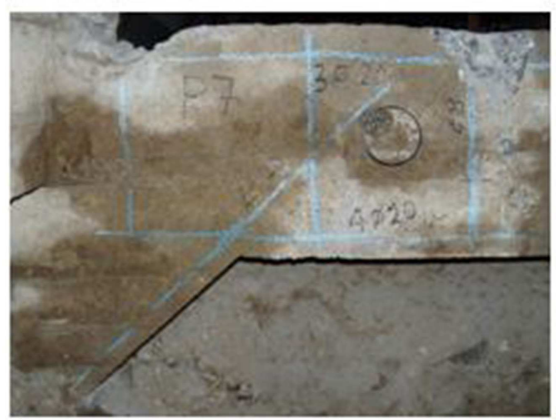

B

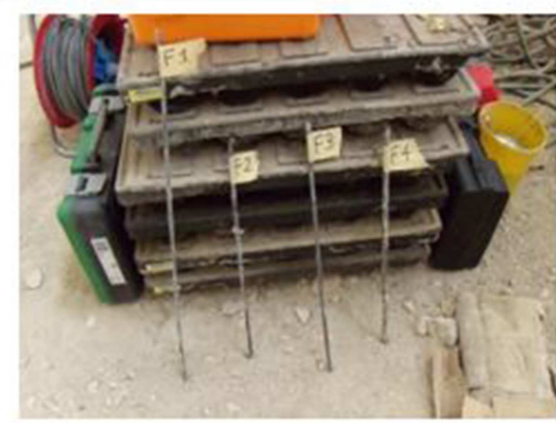

C

FIGURE 2 | Investigation campaign: (A) Material properties derived from extracted samples. N, number of samples; CV, coefficient of variation; $\mathrm{f}_{\mathrm{cm}}$, average compressive strength; $\mathrm{fym}_{\mathrm{m}}$, average tensile strength; (B) steel reinforcements disposition obtained through pacometric investigations and sampling of concrete specimen, (C) steel samples collected.

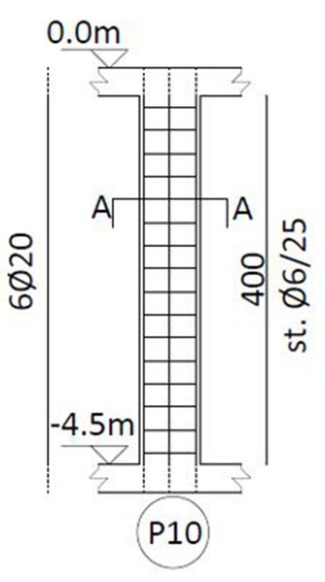

$2 \varnothing 16$

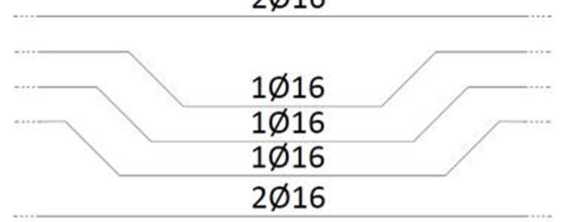

(P8)

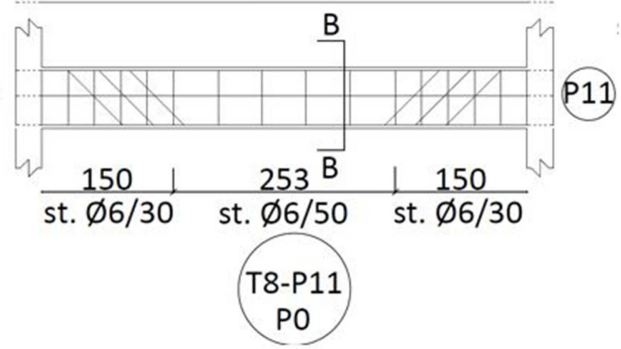

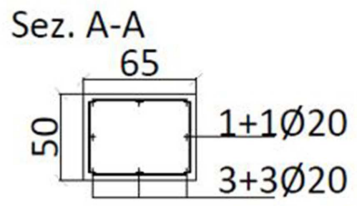

Sez. B-B $2 \varnothing 16$

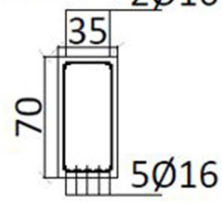

FIGURE 3 | Typical reinforcement details of columns and beams.

\section{NUMERICAL RESULTS}

In this section are illustrated and commented the results obtained with the implemented FEM models where, as described in the previous section, linear elastic frames are used. In the case of base-isolated building, the seismic devices are modeled as linear links, where friction sliders have a linear stiffness corresponding to the secant one at the considered design limit state. In all the analyses performed, the horizontal seismic action effects are evaluated with a modal analysis with response spectra, where the modal effects are combined with CQC combination rule. 


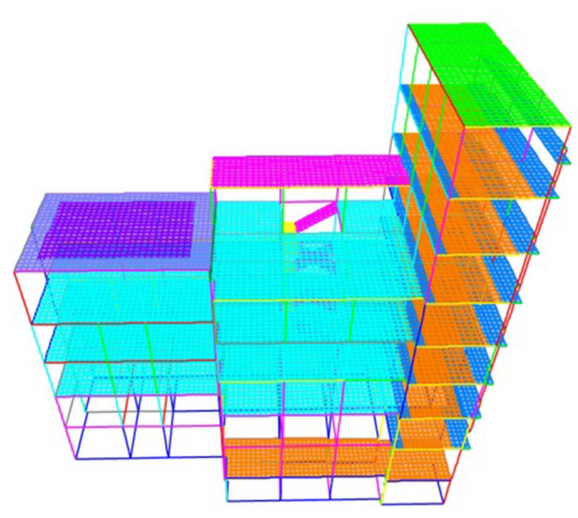

A

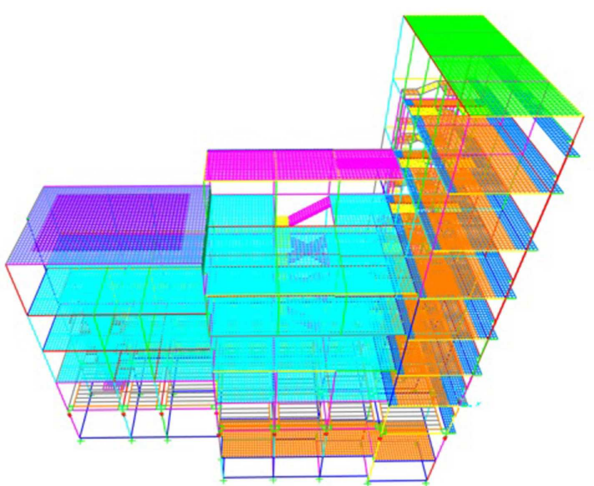

B

FIGURE 4 | 3D views of the implemented FEM model for fixed-base structure (A) and for base-isolated structure (B).

\begin{tabular}{cccccc}
$\boldsymbol{V}_{R}=\mathbf{5 0}$ years & $\boldsymbol{T}_{R}$ (years) & $\boldsymbol{a}_{\boldsymbol{g}}\left(\boldsymbol{m} / \mathbf{s}^{2}\right)$ & $\boldsymbol{F}_{\mathbf{0}}$ & $\boldsymbol{T}_{C}^{*}(\mathbf{s e c})$ \\
\hline OLS & 30 & 0.055 & 2.331 & 0.285 \\
\hline DLS & 50 & 0.073 & 2.327 & 0.313 \\
\hline LSLS & 475 & 0.205 & 2.449 & 0.362 \\
\hline CLS & 975 & 0.267 & 2.442 & 0.405 \\
\hline & & $\mathbf{A}$ & & \\
\hline
\end{tabular}

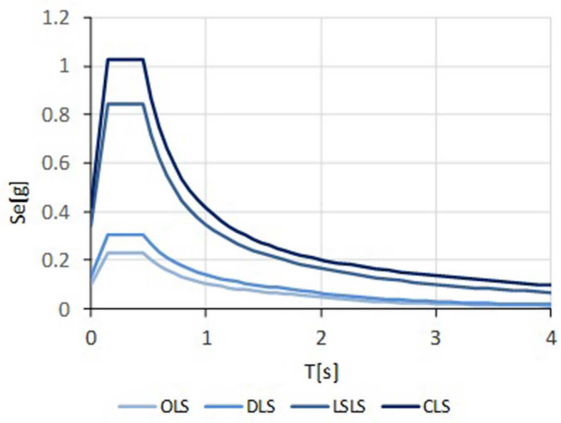

B

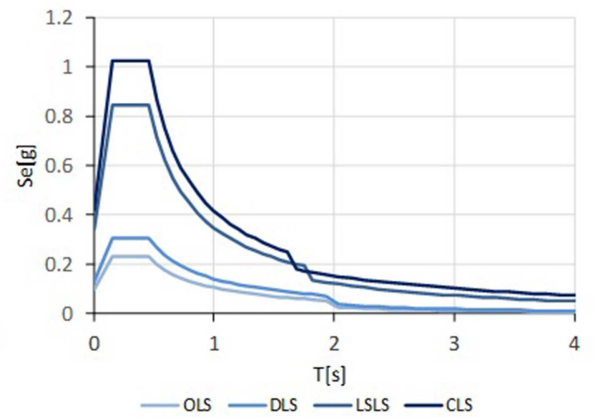

C

FIGURE 5 | Site seismic hazard and response spectra considered. (A) Parameters defining the seismic action referred to a rigid soil (Type A) for each limit state. (B) Elastic response spectra $(\xi=5 \%)$ for a soil Type C. (C) Design spectra for isolated system for a soil type C.

\section{Seismic Response of Fixed-Base Building}

The results of the modal analysis in the case of fixed-base building are reported in Figure 6 where, for brevity, are reported only the first three vibration modes. The figure illustrates the shape of each vibration mode, and reports the related vibration period $T$, the translational modal participating mass ratios along $X$ and $Y$ ( $U_{X}$ and $U_{Y}$ ), and the rotational one around $Z\left(R_{Z}\right)$. It is found that the first mode arises mainly along the $X$ direction, that is the direction along which the structure is more flexible and exhibits a more regular response. On the contrary, the second and the third modes are both roto-translational, involving a coupling of a translation along $Y$ and a rotation along $Z$.

It is interesting, for the purposes of this work, to compare the floor shear distribution over the building height as illustrated in Figure 7A, obtained by considering the seismic action acting for Life-Safety Limit State. Along both the directions the shear distribution is regular and linear as demonstrated by the high mass participation ratio of the first mode. Moreover, also a study of the shear distribution at a certain level may be done. For instance, in Figure 7B the shear distribution at Level 0 among 


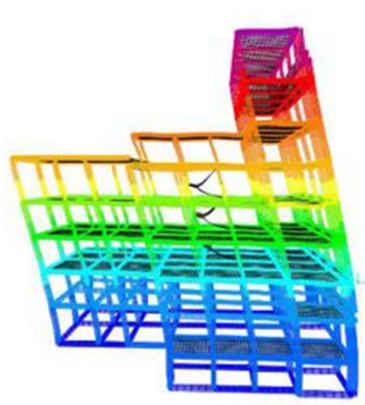

Mode 1

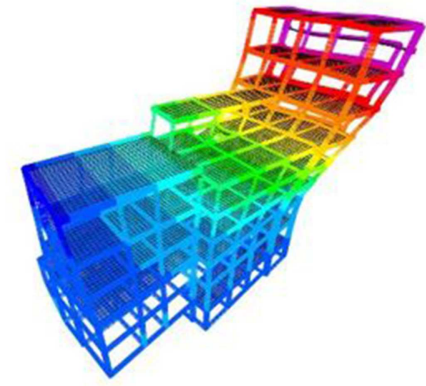

Mode 2

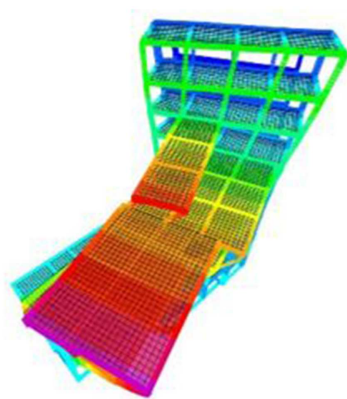

Mode 3

\begin{tabular}{|ccccc|}
\hline Mode & T [s] & Ux [\%] & Uy [\%] & Rz [\%] \\
\hline $\mathbf{1}$ & 1.683 & $67.8 \%$ & $0.0 \%$ & $0.0 \%$ \\
\hline $\mathbf{2}$ & 1.315 & $0.0 \%$ & $34.7 \%$ & $23.0 \%$ \\
\hline $\mathbf{3}$ & 1.011 & $0.0 \%$ & $18.4 \%$ & $29.4 \%$ \\
\hline
\end{tabular}

FIGURE 6 | Fixed-base model. Shapes and dynamic properties of the first three vibration modes.

the resistant frame is illustrated. As it is easy to note, the response is quite symmetric along the $X$ direction, where the only two central vertical frames (having $y=8.5 \mathrm{~m}$ e $\mathrm{y}=13.5 \mathrm{~m}$ ) absorb more than $50 \%$ of the total shear at Level 0 . By contrast, along the $Y$ direction a consistent irregularity in the response is observed. The two higher frames $(\mathrm{x}=0 \mathrm{~m}$ e $\mathrm{x}=-6 \mathrm{~m})$, representing the building tower, are stiffer, bearing a considerable amount of the floor shear. Besides the shear global distribution, in order to verify the performances for ultimate limit states, local checks of demand/capacity ratios for ductile and fragile mechanisms have been performed, according to the requirements of Italian design code (NTC, 2008). By performing these checks, it emerges that about the $15 \%$ of beams and $2 \%$ of columns don't have enough flexural or shear capacity, by considering only gravity loads. Moreover, by considering the seismic loads, almost all the columns and the $30 \%$ of beams don't have enough shear capacity.

Finally, in Figure 7C the floor drifts obtained by considering the expected horizontal seismic action for the Damage Limit State are also plotted. For brevity, in this study the maximum horizontal drifts distribution is illustrated, arising along only the Y direction. Again, as observed for the shear forces, the distribution is quite regular above the height of the building and in any case the maximum values don't exceed the $0.5 \%$, that is the limit for damage limit state indicated by the (NTC, 2008).

\section{Seismic Response of Base-Isolated Building}

The structural intervention of seismically isolating the superstructure allows a global retrofit and, simultaneously, the respect of the architectural constraints on the building, related to its historical interest. Basically, the design criterion was of reducing as much as possible the seismic action and the number of local reinforcements on the structural elements. The solution adopted is relatively easy to realize, given the fact that at a height of $-4.5 \mathrm{~m}$ the building has an existing grid of RC beams completely free from constraints, below which the insertion of the isolation devices may be done. Then, a rigid deck may be realized above the isolation devices and among the beams grid, to provide stiffness at the base of the so-obtained superstructure, and to achieve a correct behavior of devices with respect to the lateral actions. In addition, interventions are also planned for the substructure. Specifically, all sections of existing columns will be increased to permit the allocation of devices, guaranteeing adequate stiffness and providing the required resistance by also introducing additional reinforcements. Finally, also the foundation plan will be significantly strengthened with the insertion, among the base of columns, of a RC plate. Figure 8 reports a plan and an image of the chosen floor for inserting the isolation system.

As far as the base isolation system is concerned, it will be realized by the combination of two different devices, consisting of reinforced rubber elastomeric devices and flat low-friction sliders. Their arrangement and characteristics have been chosen to minimize the eccentricity between center of mass and stiffness, and to optimize both the equivalent viscous damping ratio and the system stiffness, to reduce as much as possible the seismic demand transmitted to the superstructure. In Figure 9 the schematic layout of the isolation system and the devices details are shown. Three different rubber devices are considered (Type $A 2, A 3$, and $A 4$ ) as function of the maximum vertical load capacity $\left(P_{E, \max }\right)$ required, having different lateral stiffness $\left(k_{H}\right)$ and for an equivalent damping ratio $\left(\xi_{H}\right)$ of $10 \%$, evaluated in correspondence of the maximum displacement capacity $\left(v_{\max }\right)$ equal to $400 \mathrm{~mm}$. Totally, $54 \%$ of devices are in rubber. 


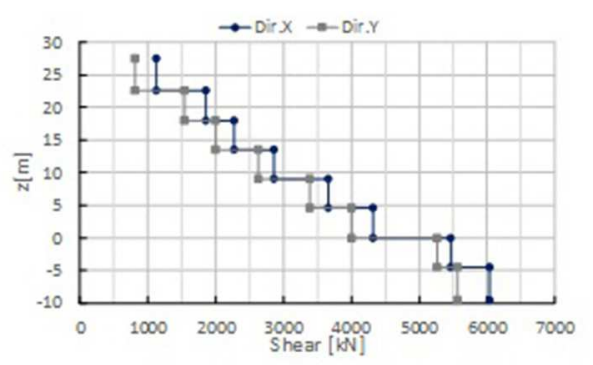

A
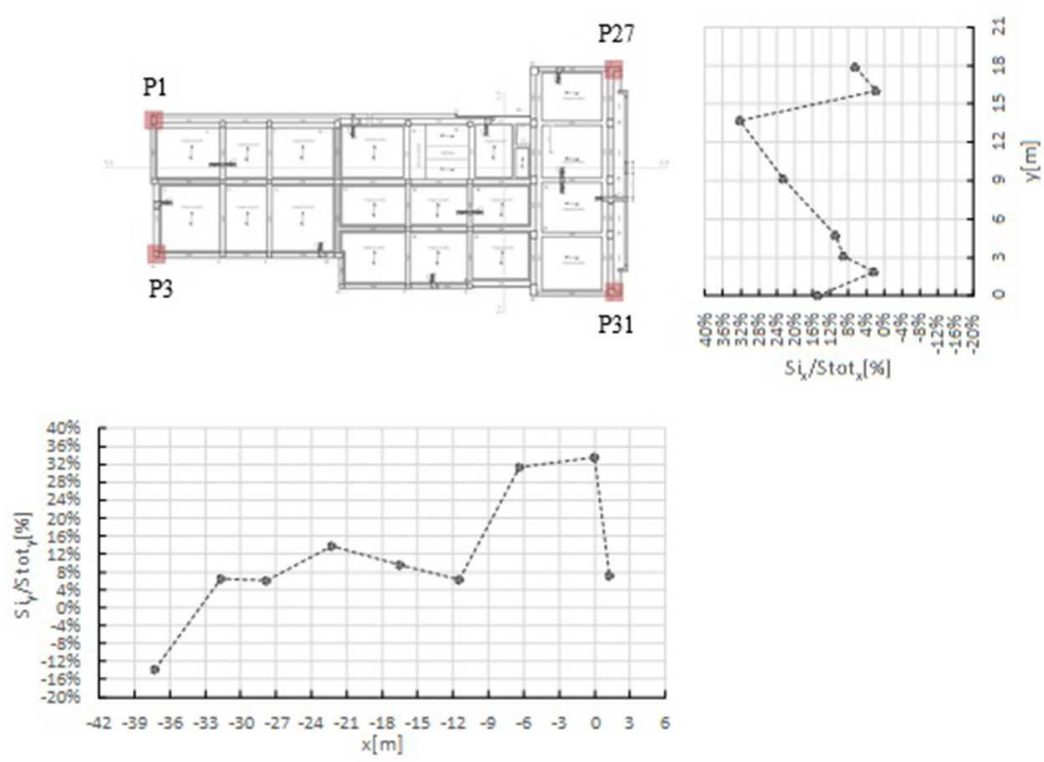

$\mathbf{B}$
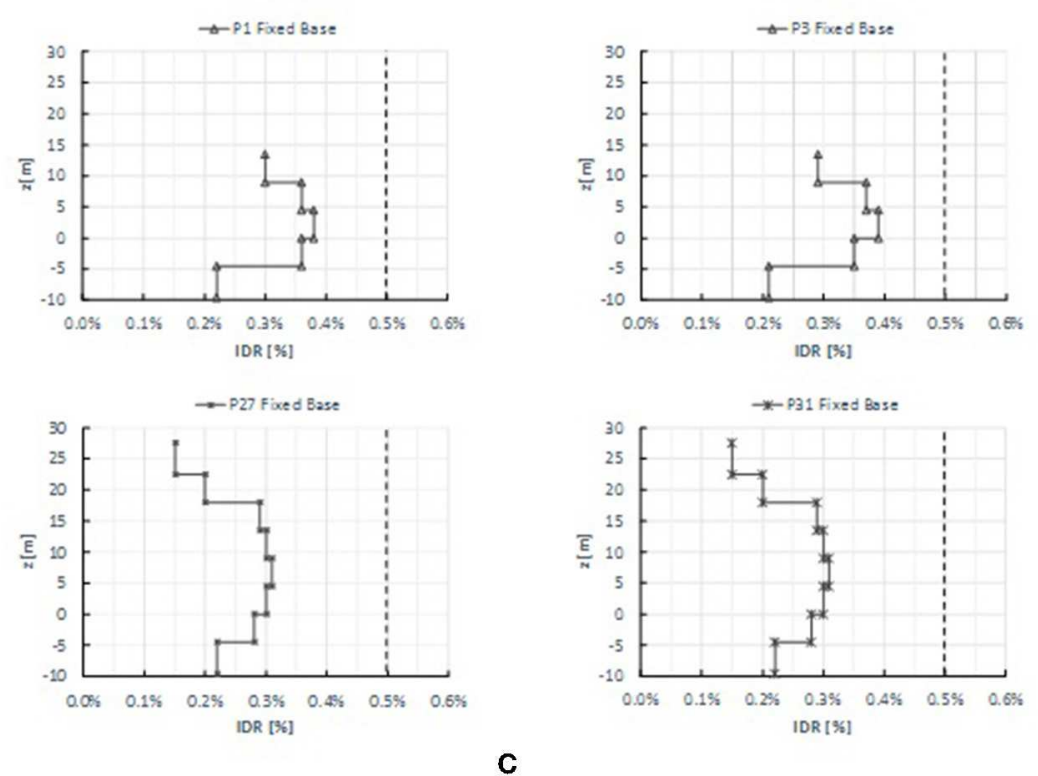

FIGURE 7 | Fixed-base model. Shear and drift distribution. (A) Shear distribution over the building height for Life-Safety Limit State, (B) shear distribution among the frames at Level 0 for Life-Safety Limit State, (C) drifts distribution over the building height in the y-direction for Damage Limit State. 


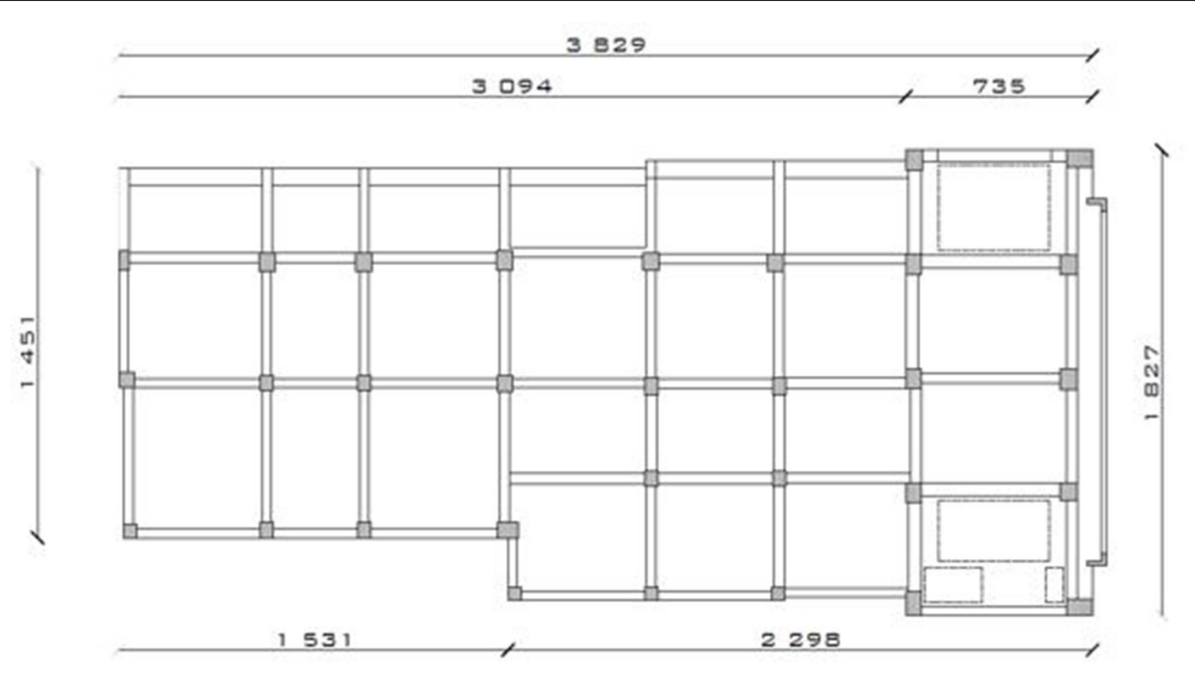

A

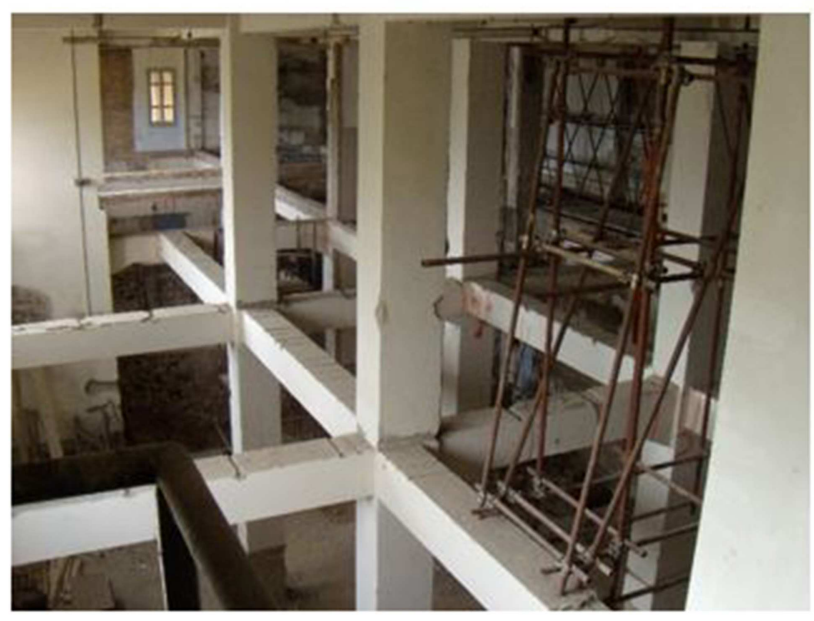

B

FIGURE 8 | Existing grid of RC beams. (A) Plan configuration (dimensions in centimeters), (B) view of current conditions.

The remaining devices are low-friction sliders with a friction coefficient $\mu$ equal to $2 \%$, modeled as equivalent visco-elastic devices, having a secant stiffness and a viscous damping ratio related to the entire energy dissipated, both calculated in correspondence of maximum design displacement. In order to maximize the system torsional stiffness, the rubber devices, where possible, have been perimetrically positioned. The Figure 9 also summarizes the equivalent linear characteristics of the isolation system for each limit state considered. More in detail, $T_{i s}$ is the period of the isolated building, $S_{e}$ is the spectral acceleration for the period $T_{i s}, K_{e s i}$ is the secant stiffness of the system, $\xi_{e s i}$ is the equivalent viscous damping ratio, $\eta$ is the reduction factor for the design spectra, $N_{L}$ is the Non-Linearity factor (Skinner et al., 1993), $S_{D e}$ is the maximum horizontal displacement of the isolation system, $S_{D e}^{*}$ is the maximum displacement of the devices assessed by considering torsional effects due to accidental eccentricity by using the expressions of Italian design code (NTC, 2008) (i.e., by multiplying the displacement obtained through response spectrum analysis by a factor $\delta=1+e / r^{2} \cdot x_{p}$ where $e$ is the considered eccentricity, $r$ is the torsional radius of the system and $\mathrm{x}_{\mathrm{p}}$ is the position of the device) and $\alpha$ is the isolation grade of the system (i.e., $T_{I S} / T_{F B}$ ).

It should be remarked that the equivalent linear characteristics of the isolation system indicated in the Figure 9 are strongly dependent on the effective properties of the isolation devices and, in particular, on the friction coefficient of the flat sliders. As known, it is strictly related to several factors such as, among the others, the axial pressure, the sliding velocity, operating temperature, consumption of the material (Mokha et al., 1988; Constantinou et al., 1990). To this aim, a series of numerical analyses have been carried out in order to evaluate the sensitivity of the seismic response by varying $\mu$ between the values $\mu$ 

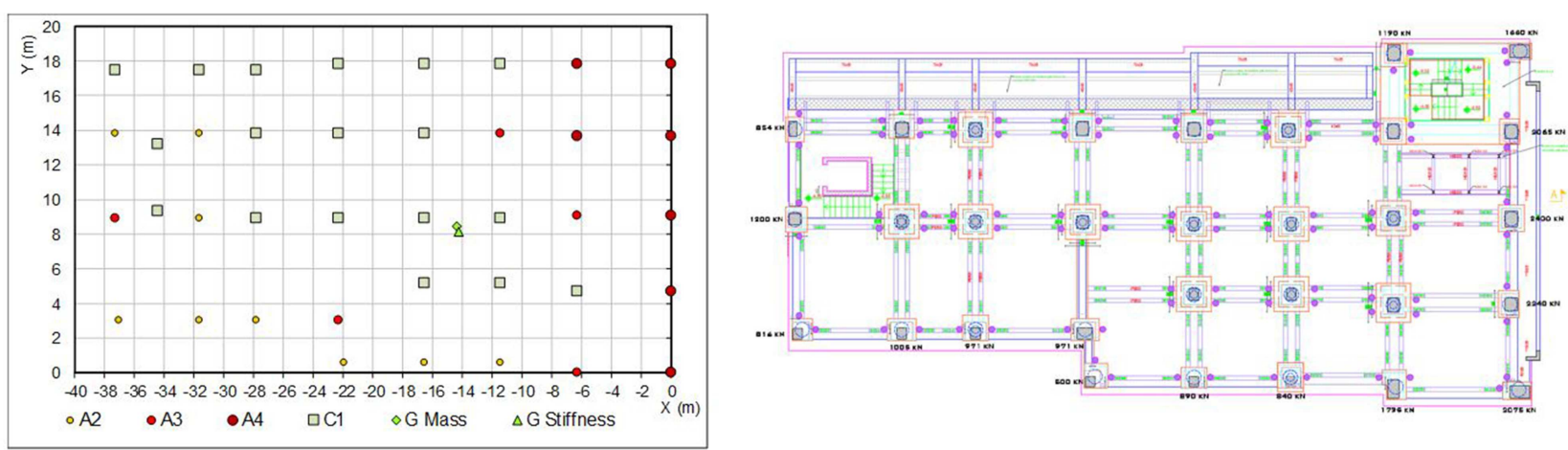

\begin{tabular}{|c|c|c|c|c|c|c|c|c|c|c|c|c|c|c|c|c|}
\hline \multirow[t]{2}{*}{ ID. } & \multirow[t]{2}{*}{ Type } & \multirow{2}{*}{$\begin{array}{c}P_{E, \max } \\
k N\end{array}$} & \multirow{2}{*}{$\begin{array}{c}k_{H} \\
k N / m m\end{array}$} & \multirow[t]{2}{*}{$\xi_{H}$} & \multirow{2}{*}{$\begin{array}{l}v_{\max } \\
m m\end{array}$} & \multirow[t]{2}{*}{$N$} & & \multirow{3}{*}{$\begin{array}{c}T_{\text {is }} \\
{[\mathrm{sec}]}\end{array}$} & \multirow{3}{*}{$\begin{array}{c}S_{e} \\
{[g]}\end{array}$} & \multirow{3}{*}{$\begin{array}{c}K_{e s i} \\
{[k N / m}\end{array}$} & \multirow{3}{*}{$\begin{array}{l}\xi_{\text {esi }} \\
(\%)\end{array}$} & \multirow{3}{*}{$\eta$} & \multirow{3}{*}{$N_{L}$} & \multirow{3}{*}{$\begin{array}{l}S_{D e} \\
{[m]}\end{array}$} & \multirow{3}{*}{$\begin{array}{l}S_{D e}^{*} \\
{[m]}\end{array}$} & \multirow{3}{*}{$\alpha$} \\
\hline & & & & & & & & & & & & & & & & \\
\hline$A 2$ & Rubber & 1240 & 0.77 & $10 \%$ & 400 & 9 & & & & & & & & & & \\
\hline A3 & Rubber & 2730 & 1.01 & $10 \%$ & 400 & 5 & oLs & 2.433 & 0.018 & 33.23 & 30.1 & 0.55 & 0.45 & 0.026 & 0.036 & 1.44 \\
\hline A4 & Rubber & 15850 & 1.25 & $10 \%$ & 400 & 7 & DLS & 2.609 & 0.024 & 28.91 & 25.1 & 0.58 & 0.37 & 0.040 & 0.053 & 1.55 \\
\hline \multirow{2}{*}{\multicolumn{6}{|c|}{ Total number of rubber isolators }} & 21 & LSLS & 2.961 & 0.090 & 22.45 & 13.9 & 0.73 & 0.11 & 0.196 & 0.235 & 1.77 \\
\hline & & & & & & 18 & CLS & 2.998 & 0.131 & 21.90 & 12.7 & 0.75 & 0.07 & 0.293 & 0.354 & 1.79 \\
\hline
\end{tabular}

FIGURE 9 | Seismic isolating system: configuration and details. Where: A2, A3, and A4 are the three types of rubber isolator considered, C1 is the flat slider, G Mass, and $G$ Stiffness are the positions of the center of masses and center of stiffness, respectively.

$=1 \%$ and $\mu=6 \%$. Figure 10 shows the following obtained results by varying $\mu$ : the resulting fundamental period $T_{i s}$, the equivalent viscous damping ratio of the isolation system $\xi_{\text {esi }}$, the demand in terms of spectral ordinate in acceleration $S_{e}\left(T_{i s}\right)$ and maximum displacement of devices $S_{D e}\left(T_{i s}\right)$. All these parameters are calculated with a FEM model implemented as described before, by considering the secant stiffness and by referring to the seismic action expected at the Collapse Limit State. As it is easy to observe by examining the obtained results, by increasing the friction coefficient $\mu$ from 1 to $6 \%$, although the equivalent isolation system stiffness increases (i.e., $T_{i s}$ reduces) the lateral acceleration $S_{e}\left(T_{i s}\right)$ transmitted to the superstructure is almost constant. This is because if $\mu$ increases also the dissipation expressed through $\xi_{\text {esi }}$ increases. Whereas, the expected maximum displacement $S_{D e}\left(T_{i s}\right)$ tends gradually to reduce, increasing the capacity/demand ratio and thus increasing the safety factor.

In Figure 11 the results of modal analyses obtained in the case of base-isolated model are reported. It is noted that the dynamic response is significantly modified with respect to the fixed-base model. In particular, thanks to the balanced arrangement of the seismic devices reducing the eccentricity between the center of mass and stiffness, a regular dynamic behavior is obtained, by activating about the $90 \%$ of mass participating with the first three modes. It is also useful, in order to quantify the benefits of the applied strategy, to compare in Figure 12 the resulting floor shears and drifts over the height with the ones obtained with the fixed-base model.
Figures 12A,B report the comparisons in terms of floor shear over the height between the fixed-base and isolated model for the LSLS action level. It can be noted that the shear demand in the case of base-isolated model is reduced more than the $70 \%$ at each level. While, in Figures 12C,D the comparisons in terms of interstory drift ratio for the DLS action level are shown. In this case the drift is reduced by over $80 \%$ between the two models, giving evidence of the effectiveness of the isolation system to contain also the non-structural damage. On this aspect, it should be observed that linear analyses do not allow to consider the impact of the effect of the of higher modes participation due to non-linearity effects, that could significantly change the shear and drift values, as observed in Braga et al. (2005). However, given the limited value of the Non-Linearity factor (Skinner et al., 1993) for the proposed system, these effects have not been taken into consideration herein.

Despite of a consistent seismic demand reduction reached with the isolation system, additional local interventions are needed in the case analyzed herein. Precisely, concrete jacketing interventions are foreseen to improve shear and flexural resistance on columns, while interventions with steel jacketing with CAM system (Dolce et al., 2001) and composite material (i.e., FRP) are foreseen as shear and flexural reinforcements on beams. Figure 13 depicts the number of local reinforcements required by increasing the level of the designing seismic action, represented as the ratio between the capacity $\left(\mathrm{agC}_{\mathrm{gC}}\right)$ and the demand $\left(\mathrm{a}_{\mathrm{gD}}\right)$, expressed in terms of ground acceleration at the LSLS. In the case analyzed, by considering a full seismic 

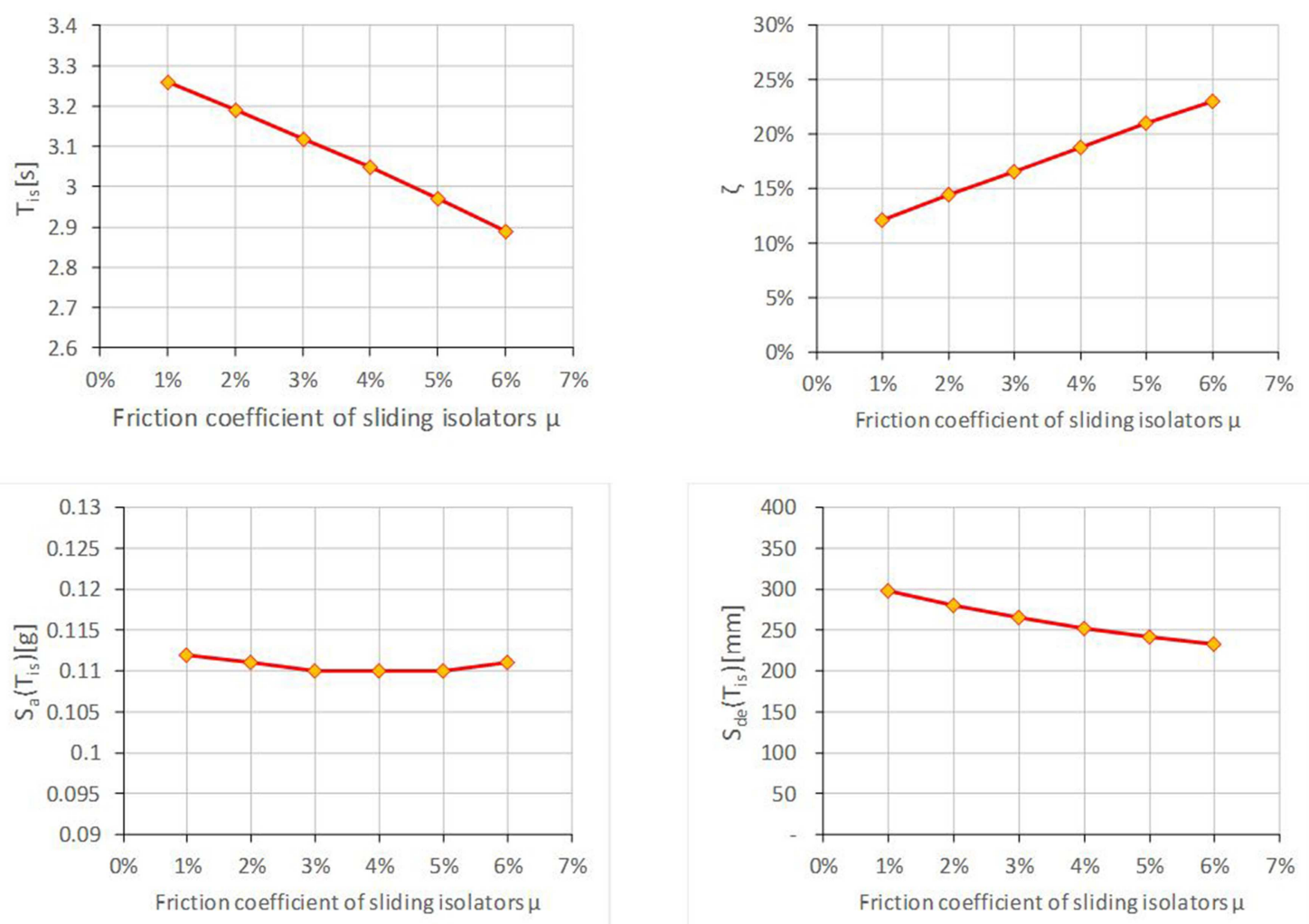

FIGURE 10 | Sensitivity analyses with the base-isolated FEM model by varying the friction coefficient of flat friction sliders.

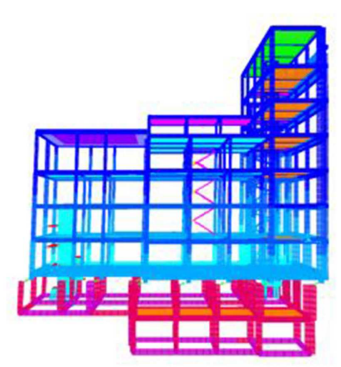

Mode 1

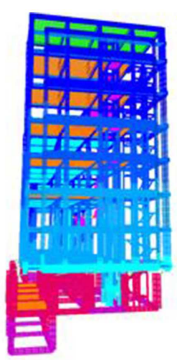

Mode 2

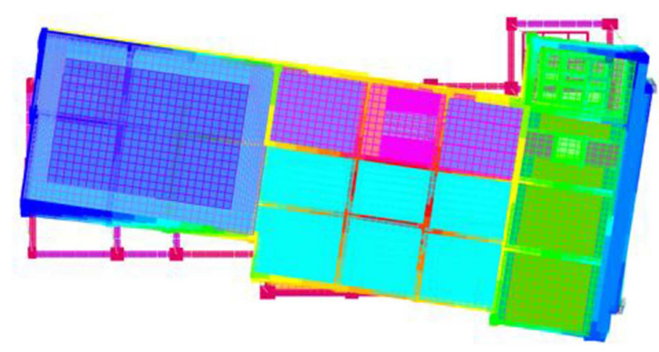

Mode 3

\begin{tabular}{|ccccc|}
\hline Mode & T [s] & Ux [\%] & Uy [\%] & Rz [\%] \\
\hline $\mathbf{1}$ & 3.463 & $89.08 \%$ & $0.02 \%$ & $0.42 \%$ \\
\hline $\mathbf{2}$ & 3.413 & $0.03 \%$ & $89.93 \%$ & $0.04 \%$ \\
\hline $\mathbf{3}$ & 3.101 & $0.67 \%$ & $0.04 \%$ & $91.79 \%$ \\
\hline
\end{tabular}

FIGURE 11 | Base-isolated model. Shapes and dynamic properties of the first three vibration modes.

retrofit (i.e., when $\mathrm{a}_{\mathrm{gC}} / \mathrm{a}_{\mathrm{gD}}=100 \%$ ), 19 interventions on columns are needed. More in detail, 12 columns need of interventions to improve shear resistance and 7 columns need of interventions to improve the flexural capacity, in both cases the intervention consists in increasing of the column section and adding of longitudinal and transverse reinforcements. Similarly, 


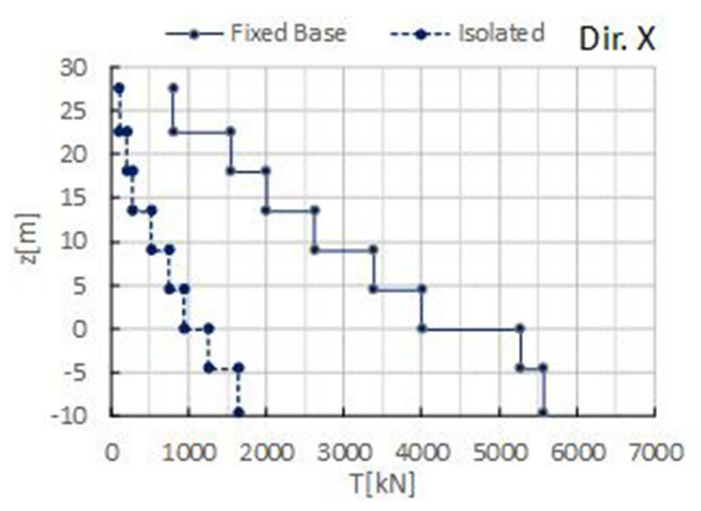

A

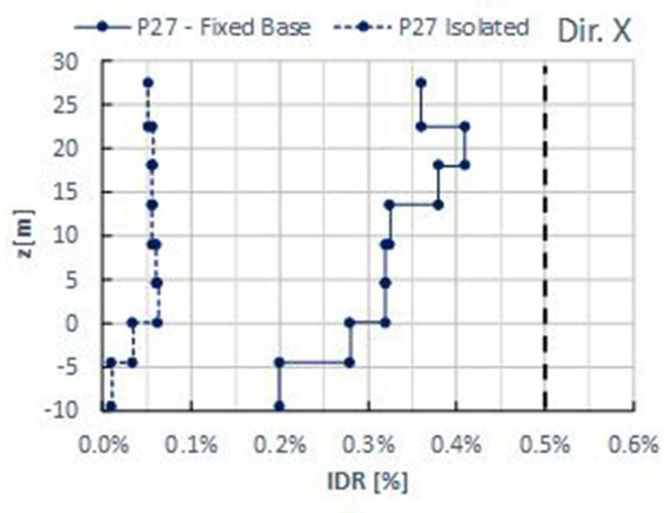

C

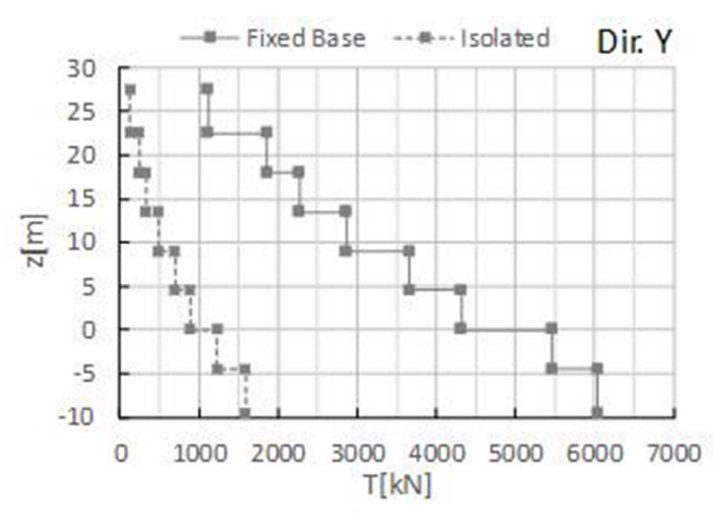

B

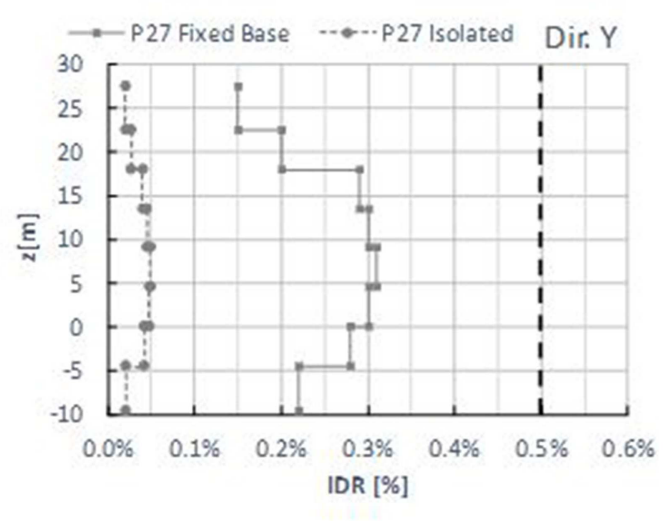

D

FIGURE 12 | Fixed-base vs. base-isolated model. Comparison over the height of floor shears (at Life Safety Limit State) for the X-direction (A) and Y-direction (B) and of Drift Ratios (at Damage Limit State) for Column 27 for the X-direction (C) and Y-direction (D).

55 interventions are needed on beams, 37 of them to improve shear resistance and 18 to improve flexural capacity. Specifically, the shear and flexural reinforcements in the support zones are provided by steel jacketing, while flexural reinforcements in the mid-span zones are provided by using FRP stripes. Three different load combinations are examined: only gravity loads, only seismic load, and both gravity and seismic loads. In Figure 13A the reinforcements needed on beams are shown, while Figure 13B reports the ones needed for columns. As it is clear to note, in this case many local reinforcements (45 reinforcements on beams and 4 reinforcements on columns) are mainly requested in order to carry on the gravity loads. Whereas, few interventions, are required for completely retrofitting the building with respect to the seismic action (i.e., obtaining a ratio $\left.\mathrm{a}_{\mathrm{gC}} / \mathrm{a}_{\mathrm{gD}}=100 \%\right)$. In detail, they are 10 for beams and 15 for columns.

The global cost of the intervention is about $330 \mathrm{e} / \mathrm{sm}$ (total 1.5 milion $€$ ). It should be observed that in these costs the realization of new structural elements are included (such as new stairs, new concrete wall systems and new decks) finalized to the architectural and functional rearrangement of the building, as foreseen in the project. The cost estimated in order to retrofit the building through traditional methods (only local reinforcements) is almost the same (about 1.5 million e). Notwithstanding the two alternative solution have the same costs, the intervention through seismic isolation is less invasive, because it drastically reduces the need of local intervention in elevation. Moreover, it guarantees a higher reliability in estimating the structural response. Furthermore, the isolating system may induce many other advantages by adopting new assessment methodologies, as proposed herein in the following.

\section{A NEW METHODOLOGY FOR ASSESSMENT OF SEISMIC RESPONSE OF A BUILDING}

In this study, it is also performed a preliminary seismic assessment of the case study with the following new methodology proposed. It is based on the idea of estimating, starting from the seismic events occurred in the past, the highest seismic action experienced by the building to which negligible or very limited damages are related. This action would become the minimum 

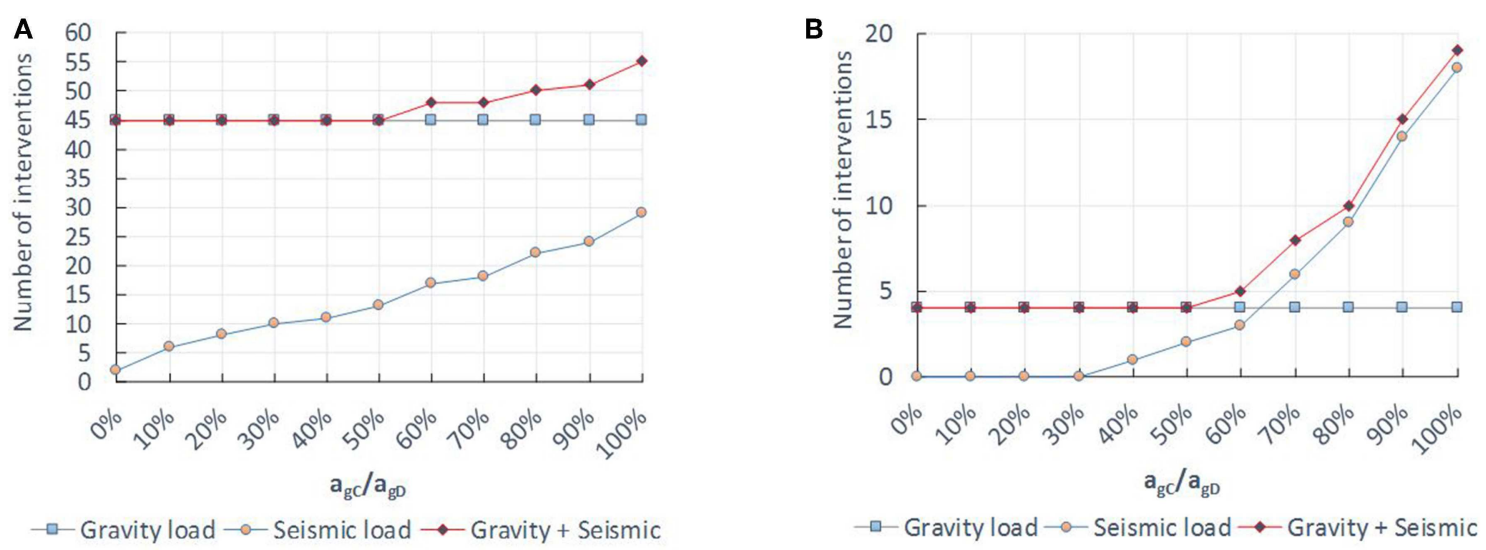

FIGURE 13 | Retrofitted structure: Number of local reinforcements on structural elements. Beams (A), columns (B).

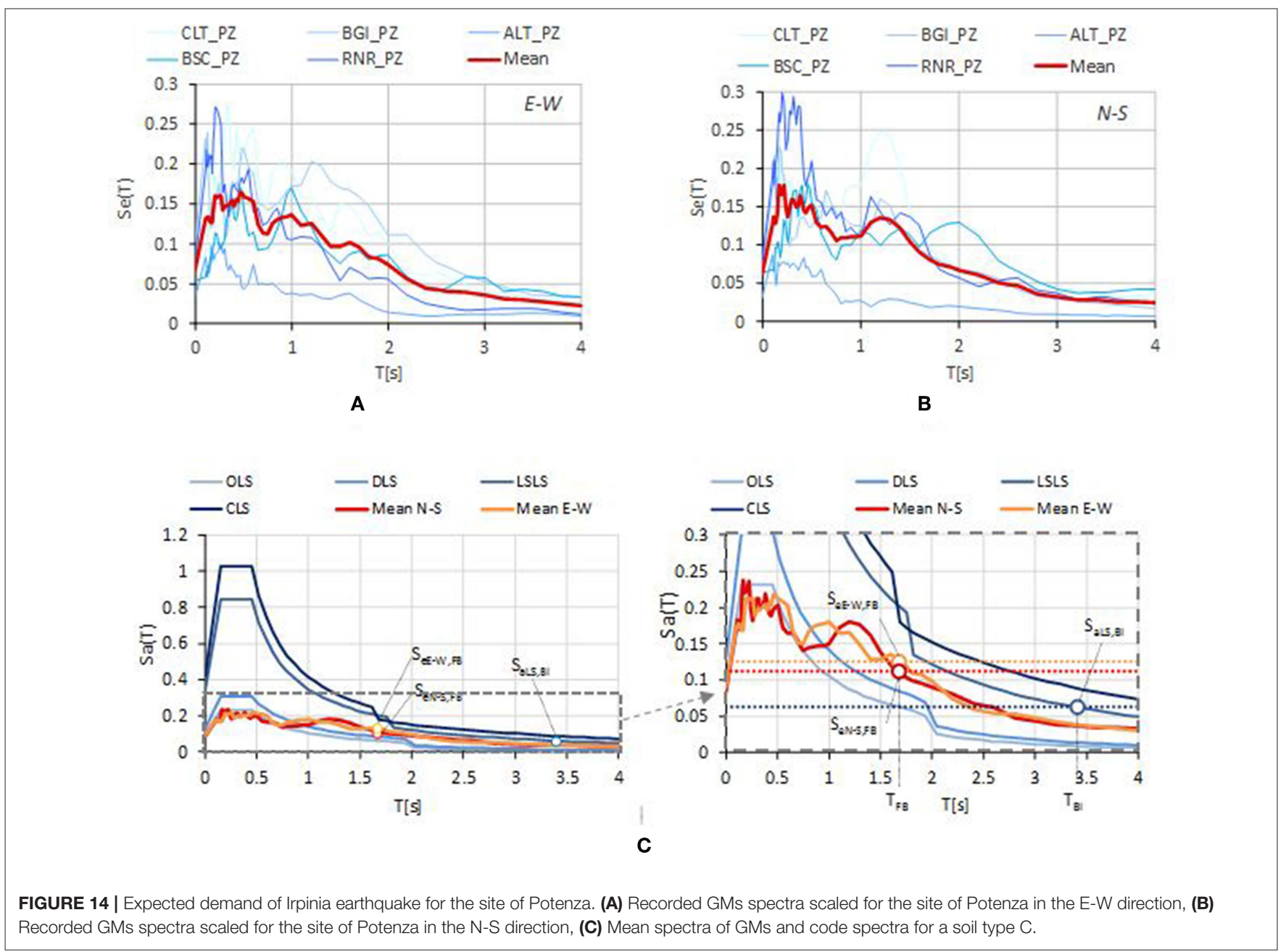

seismic action, experimentally experienced, for which the ideal superstructure of a base-isolated building would suffer negligible or very limited damages. Thus, it would represent the minimum capacity of the base isolated building.
With the aim of identifying this minimum action, an accelerometric record at the site would be ideal, even if in many cases such record is not available. Therefore, the seismic action occurred at the site should be estimated in alternative as herein 
proposed. The proposed procedure implies of using the Ground Motion Prediction Equations (GMPEs) together with the Ground Motions (GMs) recorded in the surrounding area to take into account the real characteristics of the considered seismic event and, in particular, the frequencies content actually involved. Then, the GMs records are scaled in the considered site by the means of proportioning factors, assessed by using the GMPE relationships. In this way, a rough assessment of the response spectra at the site for a certain earthquake is obtained.

In the considered case study, the procedure is applied by using the GMs record available in the ESM database (Luzi et al., 2016) and by using the GMPE proposed by Ambraseys et al. (1996). The reference earthquake is the Irpinia earthquake $\left(M_{L}=6.9\right)$ arisen in 1980, where the structure experienced very limited damages.

By considering the magnitude of the Irpinia earthquake $\left(\mathrm{M}_{\mathrm{L}}=6.9\right)$ and the epicentral distance of each accelerometric station, the elastic spectral accelerations expected at the i-th station, $\mathrm{S}_{\mathrm{a}, \mathrm{i}}^{\mathrm{GMPE}}$, can be estimated through the GMPE proposed by Ambraseys et al. (1996) as follows:

$$
\begin{aligned}
& \log \left(S_{a, i}^{G M P E}\left(T, R_{i}, M_{L}\right)=\right. C_{1}(T)+C_{2}(T) \times M_{L}+C_{3}(T) \\
& \times r_{i}+C_{4}(T) \times \log \left(r_{i}\right)
\end{aligned}
$$

where $T$ is the oscillation period, $R_{i}$ is the epicentral distance, $C_{h}$ and $h_{0}$ are coefficients given by Ambraseys et al. (1996).

Among the several records available, it has been chosen to refer to only the GMs of sites with an epicentral distance lower than the one of Potenza (epicentral distance of Potenza, $\mathrm{R}_{\mathrm{PZ}}=$ $45 \mathrm{~km}$ ). Therefore, the following 5 records are available: Calitri (CLT) (epicentral distance $R_{e p}=18.9 \mathrm{~km}$, maximum ground acceleration $\left.\mathrm{a}_{\mathrm{g}}=0.175 \mathrm{~g}\right)$, Bagnoli Irpino (BGL) $\left(R_{e p}=21.9 \mathrm{~km}\right.$, $\left.a_{g}=0.187 \mathrm{~g}\right)$, Rionero in Vulture (RNR) $\left(R_{e p}=35.5 \mathrm{~km}, a_{g}=\right.$ $0.096 \mathrm{~g})$, Bisaccia (BSC) $\left(R_{e p}=28.3 \mathrm{~km} \mathrm{ag}=0.096 \mathrm{~g}\right)$, and Auletta (ALT) $\left(R_{e p}=23.4 \mathrm{~km}, a_{g}=0.057 \mathrm{~g}\right)$. Then, the expected spectral accelerations for the site of Potenza, $S_{a, P Z}^{G M P E}$, can be assessed with the previous equations as follows:

$$
\begin{gathered}
\log \left(S_{a, P Z}^{G M P E}\left(T, R_{P Z}, M_{L}\right)=C_{1}(T)+C_{2}(T) \times M_{L}+C_{3}(T)\right. \\
\times r_{P Z}+C_{4}(T) \times \log \left(r_{P Z}\right)(3
\end{gathered}
$$

Consequently, for each oscillation period, the ratio of the spectral accelerations estimated through GMPE equations is calculated, given by the ratio of $S_{a, P Z}^{G M P E}$, for the considered site of Potenza, and $S_{a, i}^{G M P E}$, referred to the i-th accelerometric station having a $R_{i}$ epicentral distance:

$$
\alpha_{i}\left(T, R_{P Z}, R_{i}, M_{L}\right)=\frac{S_{a, P Z}^{G M P E}\left(T, R_{P Z}, M_{L}\right)}{S_{a, i}^{G M P E}\left(T, R_{i}, M_{L}\right)}
$$

For each accelerometric station considered, the so-obtained scale factor may be interpreted as a relative measure of the amplification (or de-amplification) of the spectral ordinate occurred in Potenza site with respect to the i-th site. Thus, it can be used as a scaling factor to de-amplify (or amplify) the spectral accelerations recorded (i.e., derived from the recorded GMs) at the i-th site in order to estimate the spectral accelerations occurred at Potenza during the seismic event. Then, the spectral accelerations for the city of Potenza are obtained as follows

$$
S_{a, i, P Z}^{G M}(T)=S_{a, i, P Z}^{G M}(T) \times \alpha_{i}(T)
$$

where $\mathrm{S}_{\mathrm{a}, \mathrm{i}}^{\mathrm{GM}}$ is the spectral ordinate for the $\mathrm{i}$-th recorded ground motion.

Figures 14A,B show the response spectra for bed-rock estimated for the site of Potenza starting from each of the 5 GMs chosen, scaled with the proposed $\alpha_{i}$ coefficient of the Equation (5). The spectra are separately reported for the East-West (E$\mathrm{W}$ ) and North-South (N-S) directions, considering also the mean spectrum for each direction considered. The latter, are compared in Figure 14C with the design spectra proposed by the Italian code (NTC, 2008) for different limit states, and by considering a sub-soil of Type $\mathrm{C}$ (i.e., when the velocity of propagation of seismic waves $\mathrm{V}_{\mathrm{s} 30}$ is $180<\mathrm{V}_{\mathrm{s} 30}[\mathrm{~m} / \mathrm{s}]<360$ ). In doing so, also each mean spectrum is amplified by the stratigraphic factor proposed in the Italian code (NTC, 2008) for a soil type C. As it is possible to note, the derived mean spectra are quite similar in the two directions and lower than the one of LSLS proposed by the Italian code. By considering that the fundamental vibration period of the fixed-base building is equal to $\mathrm{T}_{\mathrm{FB}}=1.683 \mathrm{~s}$ (indicated in the Figure 6), the spectral accelerations estimated through the derived spectra starting from the recorded GMs result equal to $0.13 \mathrm{~g}$ for the $\mathrm{E}-\mathrm{W}$ direction and $0.11 \mathrm{~g}$ for the N-S direction. These spectral accelerations, according to the new seismic methodology here presented, may be intended as the highest seismic action to date suffered in reality by the structure, and therefore experimentally experienced, for which the ideal superstructure of the base-isolated building would suffer negligible or very limited damages.

The so-estimated spectral accelerations are higher than the one experienced by the superstructure of the isolating building (i.e., $\mathrm{S}_{\mathrm{a}, \mathrm{LS} \text {,BIS }}=0.061 \mathrm{~g}$ by considering the fundamental period of the building related to the Life safety Limit state), that represents the spectral acceleration considered to design the base-isolated building. It must however be observed that the estimation of the mean spectra is affected by a considerable uncertainty, due to the high variability among the scaled GMs spectra of each site, as shown in the Figures 14A,B. Nevertheless, only the record of Auletta (ALT) has spectral accelerations lower than $\mathrm{S}_{\mathrm{aLS}, \mathrm{BI}}$, while all the others considered records exhibit higher values.

The proposed new methodology may be intended as a preliminary assessment of the building seismic capacity, through an analysis of its capacity exhibited during previous earthquakes, without any numerical model of the structure. Therefore, with this approach, it is possible to estimate the seismic demand to which no one or very limited interventions are required, reducing significantly their invasiveness and the structural investigations. To this regard, it should be remarked that, this design philosophy is adopted by the Italian national directive for reducing the 
seismic risk of cultural heritage (G.U. N. 47, 2011), where light interventions are permitted even in the absence of a total retrofit of the building.

\section{CONCLUSIONS}

In this paper a seismic isolation intervention on the historical building of the "Archivio di Stato" of Potenza has been illustrated. The case study is one of the first reinforced concrete buildings built in Italy, having an architectural value such that it has been included in the list of protected properties by the Italian Ministry of Cultural Heritage. This building has several architectural constraints and strong irregularities in plan and elevation. Thus, among the various available intervention techniques, seismic isolation has been chosen because it allows a strong reduction of demand on structural elements with a minimal impact on the architectural components.

The comparison between structural responses of fixed-base and isolated building has been pointed out that, despite of the low values of isolating grade (i.e., $\alpha=1.77$ for the LSLS), the isolating system is effective in order to reduce the seismic demand on the building. Specifically, the floor shear for LSLS have been reduced by over $70 \%$, while the interstory drift ratios for DLS have been reduced by over $80 \%$ at each floor. However, the strong reduction of seismic demand results not sufficient to ensure a complete retrofit of the building, requiring several local interventions.

On this aspect, it has been proposed a new and fast methodology for estimating the seismic capacity exhibited by

\section{REFERENCES}

Alhan, C., and Gavin, H. (2004). A parametric study of linear and non-linear passively damped seismic isolation systems for buildings. Eng. Struct. 26, 485-497. doi: 10.1016/j.engstruct.2003.11.004

Ambraseys, N. N., Simpson, A., and Bommer, J. J. (1996). Prediction of horizontal response spectra. Earthq. Eng. Struct. Dyn. 25, 371-400. doi: 10. 1002/(SICI)1096-9845(199604)25:4<371::AID-EQE550>3.0.CO;2-A

Braga, F., Faggella, M., Gigliotti, R., and Laterza, M. (2005). Nonlinear dynamic response of HDRB and hybrid HDRB-friction sliders base isolation systems. Bull. Earthq. Eng. 3, 333-353. doi: 10.1007/s10518-005-1242-2

Braga, F., Gigliotti, R., and Laguardia, R. (2019). Intervention cost optimization of bracing systems with multiperformance criteria. Eng. Struct. 182, 185-197. doi: 10.1016/j.engstruct.2018.12.034

Braga, F., Gigliotti, R., and Laterza, M. (2006). Analytical Stress - Strain Relationship for Concrete Confined by Steel Stirrups and / or FRP Jackets. J. Struct. Eng. 132, 1402-1416. doi: 10.1061/(ASCE)0733-9445(2006) 132:9(1402)

Caprili, S., Mattei, F., Gigliotti, R., and Salvatore, W. (2018). Modified cyclic steel law including bond-slip for analysis of RC structures with plain bars. Earthquakes Struct. 14, 187-201. doi: 10.12989/eas.2018.14.3.187

Ciampi, V., De Angelis, M., and Paolacci, F. (1995). Design of yielding or friction-based dissipative bracings for seismic protection of buildings. Eng. Struct. 17, 381-391. doi: 10.1016/0141-0296(95) 00021-X

Computers and Structures Inc (2015). SAP2000 Integrated Solution for Structural Analysis and Design. Berkeley, CA.

Constantinou, M., Mokha, A., and Reinhorn, A. (1990). Teflon bearings in base isolation II: modeling. J. Struct. Eng. 116, 455-474. doi: 10.1061/(ASCE)0733-9445(1990)116:2(455) the building during the "Irpinia earthquake" of 1980. This methodology is based on a combined use of the recorded GMs of the surrounding area in conjunction with the attenuation law (GMPE). The methodology, by avoiding an implementation of a numerical model, allows to estimate the testing seismic action occurred in reality for the superstructure of the base-isolated building to which negligible or very limited damages are related. The application of this method has shown that the spectral acceleration transmitted to the superstructure with the design Italian spectra (i.e., $S_{e}=0.061 \mathrm{~g}$ ) would result lower than the one experienced by the ideal superstructure during the "Irpinia earthquake" (i.e., $\mathrm{S}_{\mathrm{eN}-\mathrm{S}}=0.11 \mathrm{~g}, \mathrm{~S}_{\mathrm{eE}-\mathrm{W}}=0.13 \mathrm{~g}$ ), where the building exhibited very limited damages. Thus, this methodology has confirmed and certified the effectiveness of the isolating system demonstrating, in addition, that no local intervention would be necessary. In the future, the new methodology here presented may be also improved by accounting for the uncertainties such as, at first, the dispersion of the recorded GMs.

\section{DATA AVAILABILITY}

The raw data supporting the conclusions of this manuscript will be made available by the authors, without undue reservation, to any qualified researcher.

\section{AUTHOR CONTRIBUTIONS}

All authors listed have made a substantial, direct and intellectual contribution to the work, and approved it for publication.

D’Amato, M., Braga, F., Gigliotti, R., Kunnath, S., and Laterza, M (2012a). A numerical general-purpose confinement model for nonlinear analysis of R/C members. Comput. Struct. 102-103, 64-75. doi: 10.1016/j.compstruc.2012.03.007

D’Amato, M., Braga, F., Gigliotti, R., Kunnath, S., and Laterza, M. (2012b). Validation of a modified steel bar model incorporating bond-slip for seismic assessment of concrete structures. J. Struct. Eng. 138, 1351-1360. doi: 10.1061/(ASCE)ST.1943-541X.00 00588

Di Sarno, L., and Manfredi, G. (2010). Seismic retrofitting with buckling restrained braces: application to an existing non-ductile RC framed building. Soil Dyn. Earthq. Eng. 30, 1279-1297. doi: 10.1016/j.soildyn.2010. 06.001

Di Sarno, L., and Manfredi, G. (2012). Experimental tests on full-scale RC unretrofitted frame and retrofitted with buckling-restrained braces. Earthq. Eng. Struct. Dyn. 41, 315-333. doi: 10.1002/eqe.1131

Dolce, M., Gigliotti, R., Laterza, M., Nigro, D., and Marnetto, R. (2001). "Il rafforzamento dei pilastri in c. a. mediante il sistema CAM," in 10th ANIDIS Conference Lingegneria Sismica in Italia (Potenza-Matera).

Faqeer, A., Faggella, M., Gigliotti, R., and Spacone, E. (2018). Effects of bond-slip and masonry in fi lls interaction on seismic performance of older R/C frame structures. Soil Dyn. Earthq. Eng. 109, 251-265. doi: 10.1016/j.soildyn.2018.02.027

G.U. N. 47 (2011). Valutazione e Riduzione del Rischio Sismico del Patrimonio Culturale con Riferimento alle Norme tecniche per le Costruzioni di cui al Decreto del Ministero delle Infrastrutture e dei Trasporti del 14 Gennaio 2008. Italian Presidency of the Council of Ministry.

Google Maps, (2019). Google Maps. https://goo.gl/maps/BdyEstNhfyp

Ibrahim, R. A. (2008). Recent advances in nonlinear passive vibration isolators. J. Sound Vib. 314, 371-452. doi: 10.1016/j.jsv.2008.01.014 
Kawamura, S., Sugisaki, R., Ogura, K., Maezawa, S., and Tanaka, S. (2000). "Seismic isolation retrofit in Japan," in 12 th World Conference of Earthquake Engineering (Auckland).

Kelly, J. M. (1986). Aseismic base isolation : review and bibliography. Soil Dyn. Earthq. Eng. 5, 202-216. doi: 10.1016/0267-7261(86)90006-0

Kelly, J. M. (2002). Seismic isolation systems for developing countries. Earthq. Spectra 18, 385-406. doi: 10.1193/1.1503339

Laguardia, R., Gigliotti, R., and Braga, F. (2017). “Optimal design of dissipative braces for seismic retrofitting through a multi- performance procedure," in 17 th ANIDIS Conference "Lingegneria Sismica in Italia (Pistoia).

Laterza, M., D’Amato, M., Braga, F., and Gigliotti, R. (2017b). Extension to rectangular section of an analytical model for concrete confined by steel stirrups and/or FRP jackets. Compos. Struct. 176, 910-922. doi: 10.1016/j.compstruct.2017.06.025

Laterza, M., D’Amato, M., and Gigliotti, R. (2017a). Modeling of gravity-designed RC sub-assemblages subjected to lateral loads. Eng. Struct. 130, 242-260. doi: 10.1016/j.engstruct.2016.10.044

Lignola, G. P., Di Sarno, L., Di Ludovico, M., and Prota, A. (2016). The protection of artistic assets through the base isolation of historical buildings: a novel uplifting technology. Mater. Struct. Constr. 49, 4247-4263. doi: 10.1617/s11527-015-0785-1

Luca, A., De Mele, E., Molina, J., Verzeletti, G., and Pinto, A. V. (2001). Base isolation for retrofitting historic buildings : evaluation of seismic performance through experimental investigation. Earthq. Eng. Struct. Dyn. 1145, 1125-1145. doi: $10.1002 /$ eqe. 54

Luzi, L., Puglia, R., Russo, E., and Clara D'amico, M. (2016). Engineering strong motion database, version 1.0. Seismol. Res. Lett. 87, 987-997. doi: $10.1785 / 0220150278$

Martelli, A., and Forni, M. (1998). Seismic isolation of civil buildings in Europe. Prog. Struct. Eng. Mater. 1, 286-294. doi: 10.1002/pse.2260010310

Mazza, F., and Vulcano, A. (2014). Equivalent viscous damping for displacementbased seismic design of hysteretic damped braces for retrofitting framed buildings. Bull. Earthq. Eng. 12, 2797-2819. doi: 10.1007/s10518-014-9601-5
Mokha, A., Constantinou, M., and Reinhorn, A. M. (1988). Teflon Bearings in Aseismic Base Isolation: Experimental Studies and Mathematical Modeling. Technical report, NCEER, Buffalo: NY.

Mokha, A., Navichandra, A., Constantinou, M. C., and Zayas, V. (1996). Seismic isolation of large historic building. J. Struct. Eng. 122, 298-308. doi: 10.1061/(ASCE)0733-9445(1996)122:3(298)

NTC (2008). Norme Tecniche per le Costruzioni D.M. 14 Gennaio 2008. Rome: Italian Ministry of Infrastructure.

NTC (2018). D.M. 17.01.18 Aggiornamento delle 'Norme Tecniche per le costruzioni.' Rome: Italian Ministry of Infrastructure.

R.D. (1939). Norme per L'esecuzione di Opere in Conglomerato Cementizio Semplice o Armato - R.D. 16.11.1939 n 2229. Rome: Regno d'Italia.

Skinner, R. I., Robinson, W. H., and McVerry, G. H. (1993). An Introduction to Seismic Isolation. Chichester: John Wiley \& Sons.

Tomazevic, M., Klemenc, I., and Weiss, P. (2009). Seismic upgrading of old masonry buildings by seismic isolation and CFRP laminates : a shakingtable study. Bull. Earthq. Eng. 2009, 293-321. doi: 10.1007/s10518-0089086-1

Verderame, G. M., Stella, A., and Cosenza, E. (2001). "Le proprietà meccaniche degli acciai impiegati nelle strutture in c. a. realizzate negli anni 60" in 10th ANIDIS Conference "L'ingegneria Sismica in Italia (Potenza-Matera).

Conflict of Interest Statement: The authors declare that the research was conducted in the absence of any commercial or financial relationships that could be construed as a potential conflict of interest.

Copyright (c) 2019 D'Amato, Gigliotti and Laguardia. This is an open-access article distributed under the terms of the Creative Commons Attribution License (CC BY). The use, distribution or reproduction in other forums is permitted, provided the original author(s) and the copyright owner(s) are credited and that the original publication in this journal is cited, in accordance with accepted academic practice. No use, distribution or reproduction is permitted which does not comply with these terms. 